\author{
Miguel Valderrama \\ Universidad de Chile \\ miguelvalderramac@hotmail.com
}

\title{
La voz media y el siglo.
}

\section{The middle voice and the century}

\section{Resumen}

La voz media porta en historiografía la huella de un diferendo, ella anuncia una alteración o interrupción en el régimen moderno de la representación histórica. Al menos, eso es lo que parece desprenderse del uso que dan a esta expresión filósofos, historiadores y semiólogos en los debates sobre la escritura de la historia. Objeto de una atención subterránea, pero sostenida, en el orden de las humanidades y las ciencias humanas, la voz media puede considerarse el objeto del siglo, o mejor aún la "cosa" o "causa" sobre la que parece girar el siglo XX. El presente artículo presenta un primer esbozo sobre las relaciones entre la voz media y el siglo que la escenifica como novedad o repetición arcaica.

Palabras clave: voz media, representación histórica, siglo XX.

\begin{abstract}
This article presents a first outline on the relations between the middle voice and the century that staged it as a novelty or an archaic repetition. The middle voice has the trace of a dispute in historiography. It announces an alteration or interruption in the modern regime of historical representation. At least, it seems to be clear from the use of this expression by philosophers, historians and semiologists in debates about the writing of history. I would like to stablish in this essay, that the middle voice can be considered the "object of the century", or better still the "thing" or "cause" on which the twentieth century seems to be based on.
\end{abstract}

Keywords: middle voice, historical representation, twentieth century 
La voz media porta en historiografía la huella de un diferendo, ella anuncia una alteración o interrupción en el régimen moderno de la representación histórica. Al menos, eso es lo que parece desprenderse del uso que dan a esta expresión filósofos, historiadores y semiólogos en los debates sobre la escritura de la historia. Desconocida por Aristarco, y concebida como secundaria por gramáticos como Dionisio de Tracia o Apolonio Díscolo, la voz media aparece en las teorías clásicas de la lengua griega como una forma arcaica de construcción verbal subordinada a la forma activa del verbo (García Gual 1970: 1-8). En tanto tal, su presencia da testimonio de un momento en que lo personal y lo impersonal, lo activo y lo pasivo, lo interior y lo exterior, no se presentan aún separados y opuestos según el orden de representación común a las nociones de agente y persona en las lenguas indoeuropeas modernas. Constituidas en el cruce de caminos entre el lenguaje teatral, la esfera jurídica y la teología dogmática, las ideas de agente y persona incorporan desde un principio un potencial de sentido tan denso y variado, una riqueza lexical, una ductilidad semántica y evocativa de tal fuerza, de las que pareciera no poder desprenderse la propia noción de historia a pesar de todas las transformaciones sufridas por el vocablo a lo largo de los últimos siglos.

Objeto de un renovado interés tras la publicación de un largo estudio de Émile Benveniste sobre las categorías de agente y de acción en la Grecia antigua (Benveniste 1948), la voz media no ha dejado de incitar comentarios y reflexiones más allá del reducido ámbito de especialistas que inicialmente convoca su figura. La razón de este interés es histórica, y Roland Barthes pareció resumirla adecuadamente al advertir que la voz media es una noción que junto con iluminar en el presente el centro mismo de la actividad de la escritura, da cuenta además de una mutación o transformación en ese sistema general de símbolos y operaciones que se acostumbra describir bajo el término cultura. La afirmación es provocadora, y no se deja reducir fácilmente a un momento de la historia intelectual de las últimas décadas. En su apuesta, la sentencia barthesiana organiza un diagnóstico de época cuyos alcances se entrelazan con los efectos de una crítica deconstructiva del lenguaje que observa en las diferencias entre significado y significante, entre activo y pasivo, las marcas de una "extensa época", de una historia que de manera profunda e implícita se ha constituido a partir de la noción de signo, es decir, de la determinación historial del sentido del ser en general como presencia, como presencia absoluta consigo mismo, como subjetividad en tanto presencia del otro y de sí. (Derrida 1967: 23-24). 
Presentada inicialmente en 1966, en el simposio internacional The Languages of Criticism and the Sciences of Man, celebrado en Baltimore, bajo los auspicios de la Fundación Ford y el Centro de Humanidades de la Universidad John Hopkins, la comunicación "To Write: An Intransitive Verb?" (Macksey \& Donato 1970: 134-156), anuncia, en la forma de un cambio de situación, una mutación esencial en las relaciones del yo con el significante. Esta mutación afecta no solo las funciones que la crítica mantiene con lo escrito, sino que, además, da lugar a un proceso de convergencia entre literatura y lenguaje que se define en términos de "una exploración radical de la escritura" (135). A partir de una semántica y un lenguaje propios del experimentalismo y la vanguardia, la exploración y crítica de la escritura se verifica, principalmente, en el paso del verbo escribir, transitivo, al verbo escribir, intransitivo. En palabras de Barthes, este pasaje, el momento en que el verbo escribir comenzó a ser utilizado de forma intransitiva, "no siendo ya el escritor alguien que escribe sobre algo, sino alguien que escribe, absolutamente" (136), constituye ciertamente el signo de un importante cambio de mentalidad. Más allá de la mención a la noción de "mentalidad" que sirve de índice a una antropología lingüística o a una semiocrítica de amplios alcances, el desplazamiento advertido por Barthes en el uso que escritores y críticos dan en su trabajo al verbo escribir se presenta como una especie de acontecimiento que reclama una atención detenida. De algún modo, y tomando en préstamo un concepto foucaultiano no del todo ajeno al aire de familia de la comunicación, se diría que Barthes intenta identificar una especie de "umbral epistemológico", la singularidad de un acontecimiento fundador interno y externo a la modernidad de la literatura. En efecto, en lo que hay de provocación y exploración en la sentencia barthesiana, esta guarda un parecido esencial con aquella "intransitividad radical” que Michel Foucault identifica, en ese mismo año, con el nacimiento del hombre y la analítica de la finitud en Les mots et les choses (Foucault 1966: 313). En ambos ejercicios de lectura, que tienen como uno de sus ejes de indagación al signo y la literatura, se advierte la afirmación de una novedad absoluta, la constatación de una cierta extrañeza en el uso del lenguaje propia a una escena de conmoción histórica en donde vienen a encontrarse la fenomenología y el estructuralismo. Así, mientras Barthes registra esta novedad eclosionando en la literatura europea en la primera mitad del siglo veinte, en obras como las de James Joyce o Marcel Proust, en cuyo experimentalismo inscribe el trabajo de escritores franceses contemporáneos como Philippe Sollers o Alain Robbe-Grillet; Foucault, por su parte, 
entrevé esa novedad en una secuencia temporal más larga, que identifica con el nacimiento de la modernidad de la literatura y con el fin de la edad clásica a comienzos del siglo diecinueve. Pese a las diferencias de datación históricas, es posible reconocer en la simultaneidad de ambos diagnósticos un rasgo de época, la manifestación de un esfuerzo desesperado por inventariar el propio tiempo, por aprehender aquello que bajo distintas modalidades y formas se manifiesta como un agotamiento de la representación histórica, como una especie de desfallecimiento generalizado que no solo afecta a la novela y a las formas de narrar propias a un determinado concepto de historia, sino que, además, en su misma emergencia, parece arruinar la modernidad de una semántica histórica del corte que recurre a nociones tales como "mentalidad", "ruptura" o "umbral" al momento de hacer inteligibles el conjunto de sus operaciones.

Sin duda, puede leerse en Barthes y Foucault un deseo incontenible de umbral, la declaración de una experiencia y un pensamiento que reconoce en los signos del tiempo la prefiguración de un umbral único y sólido. Y sin embargo, es posible advertir de igual modo que ese deseo incontenible de pasaje, esa afirmación extrema de lo extremo, da cuenta a su manera de un abismo que se multiplica en abismos, y en donde siempre hay más de un suelo, más de un sólido y más de un único umbral. Esta multiplicación de rupturas y umbrales se puede observar ya inscrita en la noción de intransitividad reclamada por el análisis barthesiano y foucaultiano. Noción que, en última instancia, da cuenta de un antirreferencialismo, de una pérdida de "realidad" que parece conmover los cimientos culturales e históricos de un siglo que se precipita a su fin tras la larga década de los años sesenta. En tanto estos cimientos se identifican con el lenguaje, y con cierta experiencia intransitiva propia de una modernidad que ha devenido crítica de sí misma, se diría que en su deseo de tocar lo real, de testimoniar su falta, el siglo veinte encuentra en las nociones de voz media y de intransitividad un anuncio temprano de su propio desfallecimiento. En una especie de inventario de los síntomas históricos de este desfallecimiento, se suele identificar referencias a la categoría gramatical de la voz media ya en el seminario sobre las psicosis, que diez años antes, en 1956, Jacques Lacan dicta en París, en el Hospital Sainte-Anne (Lacan 1981: 317-318). En efecto, bajo el enunciado "tú eres el que me seguirás", Lacan no solo recuerda la "lección de escuela" según la cual la voz media se distingue de la activa y la pasiva por incluir dentro de sí al sujeto que constituye la acción del verbo, sino que, dando un paso más, advierte que el "sujeto que se constituye en cuanto tal en el proceso o 
estado que el verbo expresa" (317), lo hace a partir de una determinada negación, de una Verneinung, de un no-ser. De igual modo, casi doce años después del seminario sobre las psicosis, el 27 de enero de 1968, en su célebre presentación ante la Société française de philosophie, Jacques Derrida no se privará de identificar la différance con la voz media, al advertir que "lo que se deja designar como 'différance' no es ni simplemente activo ni simplemente pasivo, y anuncia o recuerda más bien algo como la voz media, dice una operación que no es una operación, que no se deja pensar ni como pasión ni como acción de un sujeto sobre un objeto, ni a partir de un agente ni a partir de un paciente, ni a partir ni a la vista de ninguno de estos términos. La voz media, una cierta no-transitividad, es quizá lo que la filosofía, constituyéndose en esta represión, ha comenzado por distribuir en voz activa y voz pasiva" (Derrida 1972: 9). El cuestionamiento del sujeto, la renovada interrogación de las relaciones del yo con el significante a que da lugar la psicosis, y la misma cadena de desplazamiento que activa la différance, se presentan como modulaciones de una indagatoria mayor sobre el tiempo y la historicidad, sobre el concepto de historia que reclama uno y otro análisis.

Sometiendo a examen el conjunto de elementos que dan lugar a un sistema histórico, que lo conforman y declaran al darlo a leer como cosa sabida, las nociones de voz media y de intransitividad constituyen los medios a través de los cuales se busca aprehender un determinado franqueamiento de la modernidad, "el día en que la finitud fue pensada en una referencia interminable consigo misma" (Foucault 1966: 329). Estos medios de anudamiento del tiempo histórico, especie de datas de una cronología que no deja de bifurcarse en umbrales y puntos de referencia, terminan por hacer de las nociones de voz media y de intransitividad vocablos-testigos de una cierta imposibilidad de testimoniar la propia verdad del tiempo, entonaciones diversas de una misma vocación, de una misma voz, de una misma disposición afectiva que en su común coloración y vibración cabría identificar con la palabra alemana Stimmung. En efecto, siguiendo la deriva conceptual del vocablo en la historia de la literatura y la filosofía alemana de los últimos dos siglos, podría observarse que la palabra se asocia menos con la armonía omniabarcante que le atribuyen Goethe o Kant, que con el principio de pérdida en que se inscribe la historia de sus transformaciones a partir de las reinterpretaciones nietzscheanas y heideggerianas (Gumbrecht 2008: 213-221; Agamben 2007: 99-114). Así descrita, la Stimmung no solo expondría un cierto estado de imposibilidad de la Stimmung, sino que además, en esa misma imposibilidad, en esa 
misma ausencia de armonía que le sería consustancial, se reconocería la propia Stimmung del tiempo presente. En evidente proximidad a Stimme, voz, la palabra Stimmung pertenece en su origen a la esfera acústico-musical, estando ligada etimológicamente a palabras latinas como concentus y temperamentum, y a palabras griegas como $\alpha \rho \mu$ ovı $\alpha$. En su origen significa entonación, acuerdo, armonía. De este sentido musical original surge el sentido moderno de "estado de ánimo". La negatividad esencial que hoy porta la palabra, sin embargo, no viene solo del uso que de ella se hace en Sein und Zeit, sino de cierto malestar, de cierta imposibilidad de estar en la historia. Las nociones de voz media y de intransitividad dan justa cuenta de este malestar, de esta disonancia al momento de conciliar y entonar el tiempo de la historia. En tanto vocablos-testigos cuyo contenido narrativo excede su propio contenido descriptivo, las nociones de voz media y de intransitividad son vocalizaciones imposibles de un estado de representación, formas fallidas de una economía de enunciación que compromete en su mismo ejercicio las categorías modernas de sujeto e historia. Esta imposibilidad de representación es de algún modo la imposibilidad de representación de un siglo, la imposibilidad de responder a la pregunta por lo real del siglo veinte, por aquel tipo de destrucción que afecta la misma escena de representación de la destrucción.

Se ha dicho que el siglo veinte está marcado por la ocurrencia de ciertos acontecimientos llamados "holocáusticos" (White 1999: 70), por la experiencia de un sublime histórico que vuelve imposible toda representación histórica según las técnicas de representación utilizadas en la investigación histórica convencional. De igual manera, se ha buscado aprehender la historicidad de estos acontecimientos acudiendo a las técnicas de representación propias del modernismo cultural, o se ha intentado caracterizar la experiencia histórica del siglo a partir de una re-caracterización de dicha experiencia como experiencia histórica sublime (Ankersmit 2010). Sin embargo, desde el momento en que se tiende a no significar nada más que lo que el siglo muestra como objeto de representación, desde el momento en que la pregunta por el siglo ocupa el lugar del objeto de la representación, se pierde definitivamente aquello que se juega en la pregunta por lo real del siglo, y que es menos un cambio o inversión de perspectiva orientada a poner al sujeto en el lugar del objeto como testigo o actor del siglo, que una interrogación por el sujeto del siglo, por aquella voz y vocalización llamada a desestabilizar la propia escena de representación que confiere unidad objetiva y subjetiva al siglo. Hay, si se quiere, una pérdida de 
objeto y de sujeto que impide que la pregunta por el siglo de lugar a un sistema histórico, aun orden de representación determinado. Esta imposibilidad de representación exige otra elaboración del pasado, exige ante todo abandonar aquello que Jean-François Lyotard denominó "la estructura lingüística comunicacional (yo/tú/él) que, conscientemente o no, los modernos acreditaron como modelo ontológico y político" (Lyotard 1988: 48-49). De ahí que no ha de extrañar que en las discusiones teóricas de la filosofía y la crítica europea continentales se haya podido declarar que "el siglo veinte es el siglo de la voz media" (Pepper 1997: 52).

Pero, ¿qué puede significar esta multiplicación de referencias a la voz media en la imaginación europea del siglo veinte? ¿A qué se debe esta suerte de apocalipsis o revelación que hace de la voz media la voz del siglo? ¿Cómo interpretar el trabajo de duelo que parece contaminar toda referencia a la voz media, haciendo de ella una manera de elaborar el duelo y una declaración escatológica a la vez, una voz enlutada en el fin de los tiempos que anuncia el fin de los tiempos? Y, por último, en el lugar del turno o del numeral de una lectura suplementaria, de una lectura que desfallece al final, en el final del comentario, ¿cómo no leer, cómo no ofrecer una glosa de la sentencia: "el siglo veinte es el siglo de la voz media", que no sea al mismo tiempo una prolongación y una interrupción de ese género de los géneros que se identifica con los textos denominados apocalípticos?

Anticipándose al momento tumbal que organiza el conjunto de ceremonias que escenifican su final, se diría que es la propia historia la que se subjetiviza en innumerables discursos y escenas que buscan dar testimonio de un desfallecimiento, de una caída, de un tumbamiento. No es casualidad, por lo demás, que 1966 sea también el año en que Hayden White publica el ensayo "The Burden of History" (White 1966: 111-134). Ensayo que no solo retoma cierta crítica sobre el valor epistemológico del conocimiento histórico, sino que proclama igualmente la necesidad de terminar con la historia, de liberar de una vez por todas al presente del peso de la historia. En palabras de White, la tarea más difícil a la que estaría llamada la "actual generación de historiadores" no sería otra que la de exponer el carácter históricamente condicionado de la disciplina histórica, con el objeto de avanzar a la disolución de la misma, junto a su reclamo de autonomía entre las disciplinas artísticas y científicas (124). Esta conminación, esta apocalíptica, no se priva de lo escatológico al momento de declarar la muerte de la historia, de concitarla entre los historiadores a partir de criptónimos como "disolución" o 
“asimilación”. Criptónimos u homónimos que buscan usurpar un lugar, una autonomía, una independencia, y, en ese extremo, en ese límite o término donde la historia viene in extremis a revelarse como peso muerto, clausurar la misma necesidad de un determinado concepto de historia, y con él la de una narratividad que parecería serle coextensiva.

Si tal como advierte Martin Heidegger, la voz media está asociada a la expresión griega

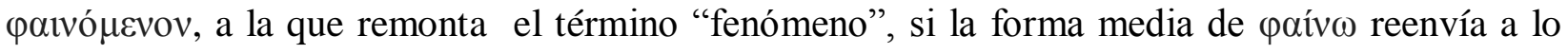
automostrante, es decir, a aquello en que algo puede hacerse visible a sí mismo (Heidegger 1997: $51)^{1}$, cabe entonces preguntar por aquello que se muestra ya desde temprano en el siglo, por aquello que dándose a leer en el trabajo de la literatura, la filosofía, la lingüística, el psicoanálisis, la semiología o la historiografía, se reserva, sin embargo, como la verdad del siglo, como aquello que éste lega a su vez como verdad de las luces, del Iluminismo, de la Ilustración. Pues si como el mismo Heidegger señala, en la forma media el fenómeno se muestra en sí mismo como lo que yace a la luz del día, como lo que es sacado a la luz, lo es siempre a condición de que lo que se manifiesta o se muestra pueda al mismo tiempo mostrarse como lo que no es, como aparecer. De ahí que se deba siempre interrogar no solo lo que sale a la luz en la voz media, sino también aquello que en la misma estructura lumínica de ese aparecer del fenómeno hace posible distinciones tales como adentro/afuera, exterior/interior, activo/pasivo. Tras esta serie de distinciones que encuentran en las luces y en lo visible sus condiciones de manifestación, se levanta la sombra de un siglo que ha hecho de la voz media su blasón, el emblema y el portaestandarte de todo aquello que en el siglo se vivió en tinieblas y oscuridad, y que en tanto tal buscó a tientas vivir un tiempo arrebatado por la pasión de lo real (Badiou 2000; Wajcman 1999). Así, si el objeto del siglo pareció ser esa passion du réel de la que testimonian, a su manera, el arte, la política y la literatura, la voz media es el modo en que se intenta aprehender la metarrealidad que es justamente la propia destrucción de la realidad.

La obsesión numerológica que data o marca de diversos modos la publicación de los textos que forman el archivo de la voz media, esa feliz o infeliz coincidencia que hace del año 1966 un año príncipe en el inventario de la voz media, no busca anunciar el apocalipsis de una catástrofe continua, antes bien tiene por propósito iluminar en su revelación la multiplicación de umbrales

\footnotetext{
${ }^{1}$ Si bien la primera edición de Sein und Zeit es de 1927, el manuscrito está fechado en Todtnauberg, en la Selva Negra, el 8 de abril de 1926. Estudios recientes sobre la génesis de Sein und Zeit advierten que el manuscrito fue escrito por Heidegger entre enero y noviembre de 1926 (Gumbricht, Hans Ulrich, 1997: 437-480).
} 
que hacen de la voz media una voz que no puede confinarse exclusivamente en una historia pasada, situada como se diría a las espaldas del presente. De algún modo, la voz media es la voz de éste y del otro siglo, una voz que viene desde la otra orilla y que en su asignificancia, en aquello que hace de ella una paraexperiencia, una forma de significación sin significado, vocaliza este tiempo como un tiempo sincategoremático, organizado a partir de una lógica del prefijo, donde la noticia del fin de los tiempos no solo denuncia un tiempo de mistagogos, sino la propia suspensión del tiempo provocada por el afecto auricular a que da lugar una escena de estremecimientos, catástrofes y admoniciones. Pero, nuevamente, cabe insistir, a propósito de la dimensión gramatológica y fonemática del fenómeno de la voz, ¿quién habla en la voz media?, ¿de dónde viene esa voz? El siglo parece callar al respecto, parece no tener oídos ni ojos capaces de captar la "cosa" que es la voz media. Si ya en el seminario sobre las psicosis Lacan caracterizaba la voz como no ligada realmente a un órgano específico del cuerpo, a una localización evidente, era porque advertía tempranamente en ella una imposibilidad de ver, una cierta ceguera común al ojo y al oído. La voz es una "cosa" imposible de ver, dirá en el seminario de 1956, es una acusmática alucinatoria que solo se revela en la angustia y en la psicosis.

En cierto sentido, la experiencia de oírse hablar, de escucharse en silencio, es el primer movimiento de autorreferencia, la acción de una pura autoafección en lo más íntimo de sí. Una autoafección que no es re-flexión, sino una pura inmediatez donde el sujeto es tanto el emisor como el receptor del mensaje, sin abandonar por ello el fuero de la interioridad. En una engañosa transparencia de sí, que de algún modo anticipa ya la propia definición de "escuela" de la voz media, el sujeto coincide en los roles de emisor y receptor sin necesidad de mediación exterior alguna. Y sin embargo, en ese mismo movimiento de autoafección, en ese movimiento que da lugar a un sujeto que se oye hablar, la voz se revela a la vez como presencia presente de una interioridad pura y como obstáculo interior a la propia presencia de sí. Definida como "elemento material refractario al significado", como "aquello que no contribuye a producir sentido" (Dólar 2006: 15), la voz es un cuerpo extraño que es a la vez lo que parece instaurar la presencia del sujeto para sí mismo cada vez que se oye hablar, al mismo tiempo que da lugar a una sensación de extrañeza o de ajenidad cuando esa misma voz es escuchada reproducida en la cinta de una grabadora o en un archivo digital. Esta escucha de la propia voz reproducida en un dispositivo sonoro parece sorprender al sujeto como la voz de otro, como una voz que no es propia, que 
parece dar testimonio de un sonido que sale del propio cuerpo y que sin embargo no se identifica con él de un modo claro, anunciando con ello, en esa suerte de des(re)conocimiento, que la llamada de la propia voz produce en el sujeto los motivos gramaticales de la voz media y de la intransitividad.

Y no obstante, la duda de si realmente es esta voz el objeto de la alocución de Roland Barthes en el coloquio de Baltimore, vuelve sobre el "objeto" que es la voz media como una duda inquietante. ¿Es la escritura intransitiva el medio en que se registra esa voz del otro y de sí que se identifica con la voz media? El barroquismo de la pregunta no debe bloquear la demanda de prestar oídos a lo que en ella se interroga. Más aún cuando se advierte, al modo de una confesión autobiográfica que Barthes desliza en 1975, casi diez años después de la comunicación "To Write: An Intransitive Verb?", que para él toda escucha deriva en scopia. "Tengo una enfermedad - confiesa en Roland Barthes par Roland Barthes-: yo veo el lenguaje. Lo que debería simplemente escuchar, una pulsión extraña, perversa, puesto que el deseo se equivoca allí de objeto, me lo revela como 'visión' [...] en la que imagino ver lo que escucho. La escucha deriva en scopia: me siento visionario y espía del lenguaje" (Barthes 2002: 755). Esta pulsión extraña, esta perversidad que hace de la voz un objeto visible, que la muestra como resto o como materia dada a ver, es también la huella de un deseo que equivocándose de objeto hace de todo lo que del significante no participa del efecto de significación un efecto de significación. La perversión de Barthes consiste en un deseo de real, de ver lo real, de acceder a ese vacío en torno al cual gira la voz en cuanto objeto parcial en el psicoanálisis. La búsqueda de este deseo, la escopia a que da lugar, hace de la interrogación barthesiana de la voz media una interrogación en torno a los límites del siglo, es decir, una indagatoria que busca aprehender el traumatismo que es el propio siglo, el objeto de representación imposible que el siglo es para la estructura lingüística comunicacional que sirve de garantía y fundamento al modelo ontológico y político de la modernidad.

En este sentido, el vínculo que se entrevé en los debates actuales entre voz y acontecimiento permite iluminar aquello que está en juego en la escena de la voz media. Escena que no oculta un deseo sonoro y escópico, pero que igualmente parece constituirse en medio de una reflexión sobre el lenguaje, sobre los límites del mundo que dicta la gramática. Sin duda, la referencia a las relaciones entre gramática y mundo impone al lector o lectora la asociación de 
nombres como los de Wittgenstein y Heidegger, en tanto referencias obligadas a tradiciones filosóficas que han hecho del lenguaje y de la gramática una de sus preocupaciones principales. Pero, de igual modo, esta misma referencia gramatical parece situar en el centro del lenguaje el problema de la voz como el escudo que el dispositivo de la persona utiliza al momento de darse un lugar en el mundo. Pues, en efecto, ya el sentido etimológico de la raíz latina de persona parece alertar sobre el hecho de que la persona existe en tanto per sonare, es decir, mientras suena a través o se manifiesta por los sonidos de la voz. En otras palabras, la persona no es otra cosa que un desdoblamiento del sujeto emisor de la voz, o aún más la máscara a través de la cual el sujeto emisor de la voz lanza un llamado, se pone en escena en una relación de interlocución, en un duelo de sí y del otro.

Las referencias sonoras a la persona, el recurso excéntrico a una filología de dudosos orígenes que hace de la voz la prótesis de la persona, el aparato ortopédico a partir del cual se constituye la persona, no tiene otro objetivo que configurar un pretexto, una especie de pie hinchado que en su desmesura termina por afectar al lenguaje y la representación. Como en la figura de Edipo, que en su misma cojera afirma y niega a la vez el movimiento de un paso, la referencia barthesiana a la voz media puede leerse como una referencia rengueante entre la voz y la persona, en tanto lo que en ella se moviliza con diversos recursos es la cuestión del sujeto, la pregunta por el enraizamiento del sujeto en el lenguaje a partir del dispositivo de la persona. Este enraizamiento da cuenta siempre de una interlocución, que Barthes ve confirmada por medio de la autoridad de la lingüística. Las relaciones entre gramatología y fonología, entre cierto discurso sobre el grama y cierto discurso sobre la fone, parecen autorizarse en efecto a través de la figura y la obra de Émile Benveniste. Es en la obra del lingüista francés, en su "claridad inagotable"

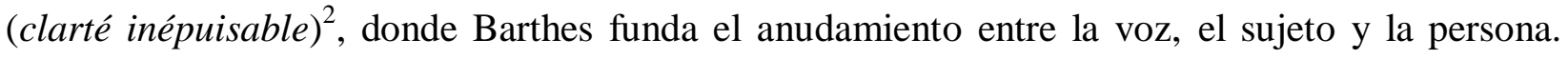
Benveniste, a su manera, lo valida al declarar que "el fundamento de la 'subjetividad' se determina por el estatuto lingüístico de la "persona", que a la "condición de diálogo le es constitutiva la de la persona, pues implica en reciprocidad que me torne tú en la alocución de aquel que por su lado se designa por yo". "El lenguaje no es posible sino porque cada locutor se pone como sujeto y remite a sí mismo como yo en su discurso. En virtud de ello, yo plantea otra

\footnotetext{
${ }^{2}$ Esta es la expresión que Barthes escoge para caracterizar el estilo de Benveniste en su reseña de Problèmes de linguistique génerale I. Reseña publicada bajo el título de "Situation du linguiste" en el número de mayo de 1966 de La Quinzaine littéraire, mismo año de la publicación del libro.
} 
persona, la que, exterior y todo a 'mí', se vuelve mi eco al que digo tú y que me dice tú. La polaridad de las personas, tal es en el lenguaje la condición fundamental, de la que el proceso de comunicación, que nos sirvió de punto de partida, no pasa de ser una consecuencia del todo pragmática" (Benveniste 1966: 260). Introducida como punto de partida, la instalación de la subjetividad en el lenguaje, crea, en el lenguaje y fuera de él también, la categoría de la persona. Una categoría que en el dominio de la subjetividad se agranda más y más en el siglo hasta anexar la expresión de la temporalidad $(262,263)$. En suma, en la categoría de la persona el dos está por fuerza inscrito en la lógica del Uno, así como el Uno tiende siempre a desdoblarse en dos para poder reflejarse, y reconocerse, en su propio interlocutor.

De la lección de Benveniste toma nota Barthes. Así, bajo el marco y el resguardo suspensivo de la pregunta por la transitividad de la escritura, la alocución barthesiana introduce en los oídos del auditorio de Baltimore la tesis de Benveniste de que la persona, la voz y la temporalidad son las categorías fundamentales del lenguaje (Macksey \& Donato: 140). Esta tesis parece modularse a través de una gramática filosófica que al mismo tiempo que le da a la persona un lugar central en el funcionamiento del lenguaje, no descuida, sin embargo, aquellos desplazamientos y resistencias que buscan desestabilizar el dispositivo de la persona a partir de figuras como lo neutro, lo impersonal o lo impropio. En consecuencia, las remisiones de Barthes a las nociones de intransitividad y de voz media retoman, a su modo, posiciones propias de una filosofía de lo impersonal abiertas tempranamente en la imaginación europea por trabajos como los que el mismo Benveniste publica a mediados de los años cincuenta. En un texto de 1956, titulado "La nature des pronoms" (Benveniste 1966:251-257), Benveniste opone efectivamente a la simetría de los pronombres yo y tú, la disimetría del pronombre él, su irreductibilidad a la díada indisoluble de la interlocución personal a que da lugar la interlocución yoltú. El pronombre él escapa a la dialéctica del Uno que la subjetivación del lenguaje absolutiza en la categoría de la persona. Pronombres como él o ella dan lugar así a una tercera persona que abre un horizonte de sentido por completo ajeno al dispositivo de la persona. Como bien advierte Roberto Esposito, "con la tercera persona ya no está en juego la relación de intercambio entre una 'persona subjetiva', el yo, y una 'persona no subjetiva', representada por el tú, sino la posibilidad de una persona no personal o, más radicalmente, una no-persona. Su ajenidad respecto a la dialéctica entre yo y tú es también una ajenidad respecto de la modalidad lógica de la persona" (Esposito 
2009: 154). Esta misma ajenidad es la que busca Barthes al indagar en el uso intransitivo del verbo escribir en la literatura y la crítica contemporánea. La apelación a nociones tales como intransitividad o voz media no tiene otro valor, en suma, que el de explorar el deseo de anonimato o de neutralización subjetiva de que da testimonio el trabajo de la literatura, la filosofía y la teoría a fines de siglo.

Ahora bien, este trabajo de desactivación de la persona puede reconocerse de algún modo como un trabajo del síntoma, como la escucha por parte del sujeto de voces, de manifestaciones auditivas propias de un delirio psicótico que es de algún modo el delirio del siglo. Este delirio, esta escucha de voces que notifican al sujeto de la inexistencia del Otro, viene a anunciar — con un saber que es saber del Otro- que el sujeto ha muerto, que no hay un Otro en quien sostenerse. El tópico de la muerte del sujeto recorre los textos y las referencias que conforman el archivo de la voz media. Ya se lea el temprano seminario sobre las psicosis de Lacan, ya se revise la reelaboración de Barthes del problema de la intransitividad en su ensayo sobre la muerte del autor $^{3}$, lo cierto es que los esfuerzos por determinar la función del verbo escribir encuentran en la cuestión más general de la muerte del sujeto su determinación fundamental.

En otras palabras, el drama del siglo veinte solo aparece de modo apropiado si se entienden las batallas manifiestas - tanto las físicas como las discursivas - como formas de expresión de una amplia agonía, de una agonía por el peso de la historia que ya desde mediados de la década de los años cincuenta se manifiesta en la forma de un "apocalipsis de lo real" (Sloterdijk 2018: 68). Las lecciones de este apocalipsis se presentan bajo las figuras de un colapso del realismo, de una desmaterialización del objeto artístico, de un agotamiento del sujeto o del fin de la historia. La misma noción de acontecimiento, pensada a través de la problemática del trauma, atravesada por ella en su misma definición, no solo da cuenta de un cambio en el modo en que la realidad se presenta en el siglo, sino que además, en tanto efecto que parece exceder a sus causas, testimonia de un traumatismo devastador que afecta la estructura lingüística comunicacional de la modernidad. De ahí que Hayden White denomine a los acontecimientos "holocáusticos" que forman e informan el siglo veinte "acontecimientos modernistas" (White 1999: 27-42), acontecimientos que no pueden ser vocalizados por economía discursiva alguna,

\footnotetext{
${ }^{3}$ La problemática de la intransitividad de la escritura parece ser paralela a la elaboración de las tesis sobre la "muerte del autor". En efecto, Barthes publica en el invierno de 1967 el ensayo sobre el autor en el número 5-6 de Apen Magazine, bajo el título de "The Death of the Author".
} 
que resisten las formas de enunciación del dispositivo de la persona, y que reclaman, en consecuencia, otra voz para nombrarlos, otra economía de enunciación.

\section{Bibliografía}

Agamben, G. (2007). La potencia del pensamiento. Ensayos y conferencias, trad. Flavia Costa y Edgardo Castro, Buenos Aires: Adriana Hidalgo.

Ankersmit, F. (2010). La experiencia histórica sublime, trad. Nathalie Schwan, Ciudad de México: Universidad Iberoamericana.

Badiou, A. (2000). Le siècle, Paris: Seuil

Barthes, R. (2002). Roland Barthes par Roland Barthes [1975], Ouvres completes, tomo IV, 1962-1967, edición revisada, corregida y presentada por Éric Marty, Paris: Seuil.

Barthes, R. (1970). “To Write: An Intransitive Verb?”. En Richard Macksey y Eugenio Donato (eds.). The Structuralist Controversy. The Languages of Criticism \& the Sciences of Man, Baltimore: Johns Hopkins Press.

Benveniste, E. (1948). Noms d'agent et Noms d'action en indoeropéen, Paris: AdrienMaisonneuve.

Benveniste, E. (1966). Problémes de linguistique générale I, Paris: Gallimard.

Derrida, J. (1967). De la gramatologie, Paris: Minuit.

Derrida, J. (1972). Marges de la philosophie, Paris: Minuit.

Dolar, M.(2006). A Voice and Nothing More, Cambridge: The MIT Press.

Esposito, R. (2009). Tercera persona. Política de la vida y filosofía de lo impersonal, trad. Carlo Molinari, Buenos Aires: Amorrortu.

Foucault, M.(1966). Les mots et les choses. Une archéologie des sciences humaines, Paris: Gallimard.

García Gual, C. (1970). El sistema diatético en el verbo griego, Madrid: Instituto Antonio Nebrija.

Gumbrecht, H. (2008). "Reading for the 'Stimmung'. About the Ontology of Literature Today", Boundary, 2/35, 213-221;

Gumbricht, H. (1997). 1926: Living at the Edge of Time, Cambridge: Harvard University Press.

Heidegger, M. (1997). Ser y tiempo, trad. Jorge Eduardo Rivera, Santiago de Chile: Editorial Universitaria.

Lacan, J. (1981). Le Séminaire. Livre III, Les psychoses, 1955-1956, Paris: Seuil. 
Lyotard, Jean-François (1988). Le Postmoderne expliqué aux enfants. Correspondance 19821985, Paris: Galilée.

Pepper, T. (1997). Singularities. Extremes of Theory in the Twentieth Century, Cambridge: Cambridge University Press.

Sloterdijk, P. (2018).¿Qué sucedió en el siglo XX?, trad. Isidoro Reguera, Madrid: Siruela.

Wajcman, G. (1999). L'Objet du siècle, Paris: Verdier

White, H. (1999). Figural Realism. Studies in the Mimesis Effect, Baltimore: The Johns Hopkins University Press.

White, Hayden (1966). “The Burden of History”, History and Theory, vol. 5, núm. 2, 111-134. 